To cite this article: İneç, Z.F. (2021). Developing a Geo-game Application for Global Connections in Social Studies Teaching: Gezgin Case. Romanian Review of Geographical Education, 10(1), 36-55. DOI: $10.24193 /$ RRGE120213

\title{
DEVELOPING A GEO-GAME APPLICATION FOR GLOBAL CONNECTIONS IN SOCIAL STUDIES TEACHING: GEZGİN CASE
}

\author{
ZEKERİYA FATİH İNEÇ \\ Erzincan Binali Yildirim University, Faculty of Education, Erzincan, Turkey, \\ e-mail: fatihinec@erzincan.edu.tr
}

(Received: January 2021; in revised form: February 2021)

\begin{abstract}
This study investigated the developmental process of a dynamic geo-game, Gezgin, which was developed by the researcher based on the Four-Component Instructional Design (4C/ID) Model, and its benefits in the acquisitions, values and skills of the Global Connections learning area of the social studies curriculum applied in Turkey. It also determined Gezgin's reflecting acquisitions, values, and skills, as well as social studies education experts' opinions about Gezgin. A case study approach was adopted and five experts participated. The data collection lasted for approximately fourteen months due to the development process of Gezgin. Most of this process coincided with the COVID-19 pandemic period. The data were descriptively analysed and the experts' evaluations were subjected to content analysis. Findings indicated that Gezgin mostly reflected the acquisitions, values, and skills of Global Connections learning area and could support the curriculum as a studying environment, create various experiences, materialise theoretical knowledge, and that it could be tested on students. It was also understood that values, primarily, and skills and acquisitions, subsequently, were mostly supported. Although the results of the study revealed similarities with the results of other studies in scientific literature, it differed from them as a large platform where the acquisitions, values, and skills of a learning field were reflected. The results indicated that geogames should be used to support other learning areas, develop high-level skills, and create a level of awareness in accordance with spatial citizenship skills.
\end{abstract}

Keyw ords: geo-games, geographic information systems, 4C/ID instructional design model, Gezgin

\section{NTRODUCTI ON}

The rules and organizations of games and playing games as a habit of humankind are based on geographic data. Even the roots of chess, which dates back to ancient times, and of an augmented reality (AR) mobile game "Pokémon Go!", which has been a phenomenon for a period, are based on 
geography. Especially since the 2000s, the widespread access to technology has accelerated the emergence of new digital games based on geography (Ahlqvist \& Schlieder, 2018).

Unlike traditional computer games, these games, focusing on acting in a real-world environment and allowing the reflection of skills and efforts in activities, provide the opportunity of organizing and exploring the content and of entertaining the players (Kiefer, Matyas \& Schlieder, 2006). Currently, the preferences of players have been in favour of games that are based on locations in real-world geography rather than games in which objects are moved with simple movements. One of the digital games designed within this framework is the geo-game (Schlieder, Kiefer \& Matyas, 2006).

Geo-games, considered a dimension of geographic information systems, are defined as games based on geographic location (Schaal et al., 2018). Geographic information systems, which have especially gained an interactive structure with Web 2.0, have become prominent in learning processes and in daily life. Geo-games, which have become popular with AR game "Pokémon Go!", are one of the platforms where various acquisitions and skills are integrated attracting the attention of developers and researchers.

Even scientific design examples have been created for geo-games which are labelled as serious and fun. Within this framework, the geogames analysed in the scientific studies carried out by a number of studies such as Ahlqvist et al. (2014), Feulner \& Kremer (2014), Ihamaki (2015), Kiefer, Matyas \& Schlieder (2006), Paulus, Scheriau \& Piechl (2007), Schaal, Schaal \& Lude (2015), Schaal et al. (2018), Schlieder, Kiefer \& Matyas (2006), Tomaszewski \& Schwartz (2017), Tomaszewski et al. (2020) were evaluated in terms of various variables.

The focus on the studies carried out on geo-games in specific periods can be explained by the developments in web technologies, and the focus on geographic data-based skills can be explained by the geography technology combination. However, there has been no geo-games application developed with instructional design processes related to social studies and social studies curriculum in the scientific literature.

Moreover, one of the common points of the social studies course is that it has important functions such as preparing citizens in the concretization of basic principles like acculturation, method, and time (Safran, 2014, pp. 5 8 ) and the realization of learning activities based on problem-solving through geo-games (Doğanay, 2016, pp. 404-405). Therefore, a geo-game with an instructional design process was developed to support the acquisitions, values, and skills of the Global Connections learning field in the social studies curriculum applied in Turkey. In this study, the preference of the learning area is that the knowledge at the local level reaches a global dimension by going beyond the borders, and the need for students to gain awareness of these issues due to the cooperation and competition of states by showing similar behaviours. Thus, it is seen that it aims to prepare effective Turkish Citizens who can perceive the changes of the world and develop awareness (Ministry of National Education [MoNE], 2018). 
Accordingly, issues such as recognition of different societies and cultures, perception of global problems and economic relations are covered within the scope of learning (Oturak Eyecisoy, 2014, p. 44). This content offered to fourth, fifth, sixth, and seventh grades includes sixteen acquisitions, three values and seven skills. The foreseen acquisitions, values and skills are explained in detail in the 4C/ID instructional design process. In accordance with this purpose, there were two basic questions that the study sought answers to through social studies experts. These were:

Question 1: How are the acquisitions, values, and skills in the Global Connections learning field reflected in Gezgin? Complementary questions were addressed to social studies education experts:

1. What are your views on reflecting the acquisitions related to the global learning field on Gezgin?

2. What are your views on reflecting the values related to the global learning field on Gezgin?

3. What are your views on reflecting the skills related to the global learning field on Gezgin?

Question 2: What are your views on Gezgin?

\section{Purpose of the research}

In this study, the process of developing a dynamic geo-game called Gezgin, in four stages, was explained according to the 4C/ID instructional design model to support the acquisitions and skills of global connections learning area in social studies teaching domain in Turkey and to prioritise the values (e.g. peace and respect) predicted in the national curriculum of social studies teaching (see MoNE, 2018). In this sense, it was aimed to analyse the reflection of the acquisitions, values, and skills on Gezgin and the opinions about the digital environment through expert opinions.

\section{I mportance of the research}

The study was important in terms of developing a geo-game application for the social studies teaching course. The literature states that the studies focusing on the improvement of mapping skills are limited and much research is needed. Furthermore, Gezgin was possible to reflect the acquisitions, values, and skills of a learning area included in the social studies curriculum implemented in Turkey. Within this framework, the application supported sixteen acquisitions, three values, and seven skills of the fourth, fifth, sixth, and seventh grades.

The dynamic architecture of the application also provided the integration of content organization related to other learning areas such as (1) individual and society, (2) culture and heritage, (3) people, places, and environments, (4) science, technology, and society, (5) production, 
distribution, and consumption, and (6) active citizenship. The application was based on evidence and game-based learning while sharing the digital notes of travellers. Therefore, it differed from serious geo-game applications; however, it still did not differ completely from this structure. This structure of the application was called the hybrid model by the researcher. The absence of a similar application in Turkey with prominent sides of the study indicated that this research could fill a serious gap in social sciences education.

\section{METHOD}

\section{Research model}

Case study design as one of the qualitative research approaches was preferred to determine expert experiences at a certain time interval, obtaining detailed information about the geo-game (Creswell, 2015, p. 97). Standardised open-ended interviews were performed to determine the views of the social studies education experts related to acquisitions, values, and skills in the environment after the development process of the geogame. Therefore, following the nature of a case study, the experiences of the experts on the environment were determined in detail. Concepts and relationships were obtained by analysing the findings with content analysis (Yıldırım \& Şimşek, 2013, p. 259).

\section{Study group}

The study was carried out with five social education studies experts (Table 1) who were determined with typical case sampling as one of the maximum diversity sampling methods. The obligation of selecting individuals who had sufficient knowledge on identifying certain situations among the innovations that Gezgin brought to the field was one of the reasons for preferring this method (Yıldırım \& Şimşek, 2013, p. 138). Thus, Gezgin's evaluation process is limited to five social studies education experts. These experts' gender and level of education are provided in Table 1.

Table 1. Study group

\begin{tabular}{lll}
\hline Nickname & Gender & Level of Education \\
E1 & Female & Master's degree \\
E2 & Female & Doctorate degree \\
E3 & Male & Master's degree \\
E4 & Male & Master's degree \\
E5 & Male & Doctorate degree \\
\hline
\end{tabular}




\section{Data collection tools}

A semi-structured interview form was created to determine the opinions of social studies experts related to Gezgin and the acquisitions, values, and skills it supported. This form was converted into an online format and shared with an access URL with the study group, via social media accounts. The questions in the form were the ones that the study sought answers to.

\section{Data analysis}

Descriptive analysis was used to summarize and interpret the data related to the first question obtained from social studies education experts via an online form according to previously determined themes (Yıldırım \& Şimşek, 2013 , p. 256). These themes were acquisitions, values, and skills creating the Global Connections learning area.

The experts' general opinions were evaluated using content analysis. The themes were created in the context of the meanings determined with this analysis that was especially used in case studies (Patton, 2018, p. 453). For determining the reliability level of the analysis, the opinions of three social sciences experts were asked, and the reliability calculation was made with the formula developed by Miles and Huberman (1994). This formula performs a reliability check by ensuring that data sets become meaningful and compatible after they are encoded. Thus, the reliability of the descriptive analysis was calculated to be $100 \%$, and the reliability of the content analysis was $92 \%$. The high reliability of descriptive and content analysis is due to the experts' mastery of the acquisitions, values and skills in the social studies curriculum and their direct reflection on their opinions. The fact that these values obtained for both analyses are above the predicted value of $90 \%$ intercoder fit shows that the performed analysis meets the criteria (Miles \& Huberman, 1994, p. 64).

\section{Research process}

The study had two different stages in terms of developing Gezgin and of determining the experts' evaluations of the environment and acquisitions, values, and skills. Within this context, Gezgin was primarily developed in twelve months, between 2019 and 2020, and then evaluated by experts within two months. Thus, a part of the development process of the application and the entire evaluation process by the experts coincided with the COVID-19 pandemic outbreak.

\section{Material}

A geo-game application called Gezgin was developed by the researcher to carry out the study. For this purpose, instead of designing a game engine, the web mapping service engine of an internet-based geographic information systems application named Seyyah (İneç, 2012) was considered 
to reflect the nature of geo-game type games and developed by the researcher according to the ADDIE (Analysis, Design, Development, Implementation, and Evaluation) instructional design model. Seyyah, which was used to calculate latitude and longitude, could also make the content dynamic. Developed on Seyyah's web mapping service, Gezgin was created in four stages (learning tasks, supportive information, procedural information, and part-task practice), with the 4C/ID instructional design model focusing on the development of complex skills and reflecting new learned information into daily life (van Merriënboer, 2019, p. 3).

Gezgin is published via the domain name http://www.precoder.net for users to access. After accessing Gezgin with Internet browsers, students encounter routes, markers and a special character on the world image taken from the satellite. Students move the character on the routes to reach the markers. Markers allow navigator notes to be displayed with multimedia elements in pop-up windows. These notes are created with content that is thought to reflect the acquisitions, values, and skills of the Global Connections learning field. Thus, by moving the character on the map, students reach the traveller notes and then explore the world. There are no definite rules for these events held at Gezgin. It is expected from students to examine traveller's notes by following the alternative routes. Then, the duration of the game is determined by the users. Since it will take time to review traveller's notes, the game should be spread over a wide period in a planned manner. This situation caused the evaluation of the application by social studies education specialists to take approximately two months. The hybrid nature of Gezgin ensures that students are expected to have fun while playing games and to behave seriously due to the content. It is possible to adjust the difficulty level of the game through the dynamic architecture of the Gezgin. However, in this study, no difficulty level is determined.

\section{Learning tasks}

This stage, considered as the basis for the curriculum, ensures real-life activities to be performed as student-centred. In fact, these activities are transferred to task environments in the geo-game created by simulation technique. Accordingly, learning tasks are required to create a link between future and daily life and reflect knowledge, skills, and attitudes.

When the learning tasks are evaluated within this framework, it is noticed that it has a structure that proceeds from specific to general and is based on learning by doing and experiencing. These tasks should also be constantly changing in terms of content in a real-life context, adjust complexity levels, and include support and guidance services (van Merriënboer, 2019, pp. 4-5). In accordance with this information, the simulation environment of Gezgin learning tasks was drafted. A world map (Stöckli, 2004) obtained from NASA's visible Earth catalogue was integrated into Gezgin and introduced to the database. For learning tasks to be realistic, moving cloud effects were added to the world image as an upper layer. Subsequently, information on latitude and longitude was transferred 
to the database determining the locations in line with the acquisition and content in the Global Connections learning area.

To perform the simulation technique, the locations matched with the database were connected to each other with flag and road graphic layers and transformed into a dynamic structure in accordance with the supportive information stage. This way, learning tasks could vary, their complexity levels could be adjusted, and both support and guidance services could be accessed. Accordingly, the learning tasks created with real-world problems in the game included a long and difficult virtual journey. The player character, which the student moves as a traveller, begins his journey through Turkey, where it is located. This character is Nasreddin Hodja, who has an important place in Turkish culture in terms of values and was drawn by the researcher. Thus, the concretization of Nasreddin Hodja's journey was provided (Figure 1 ).

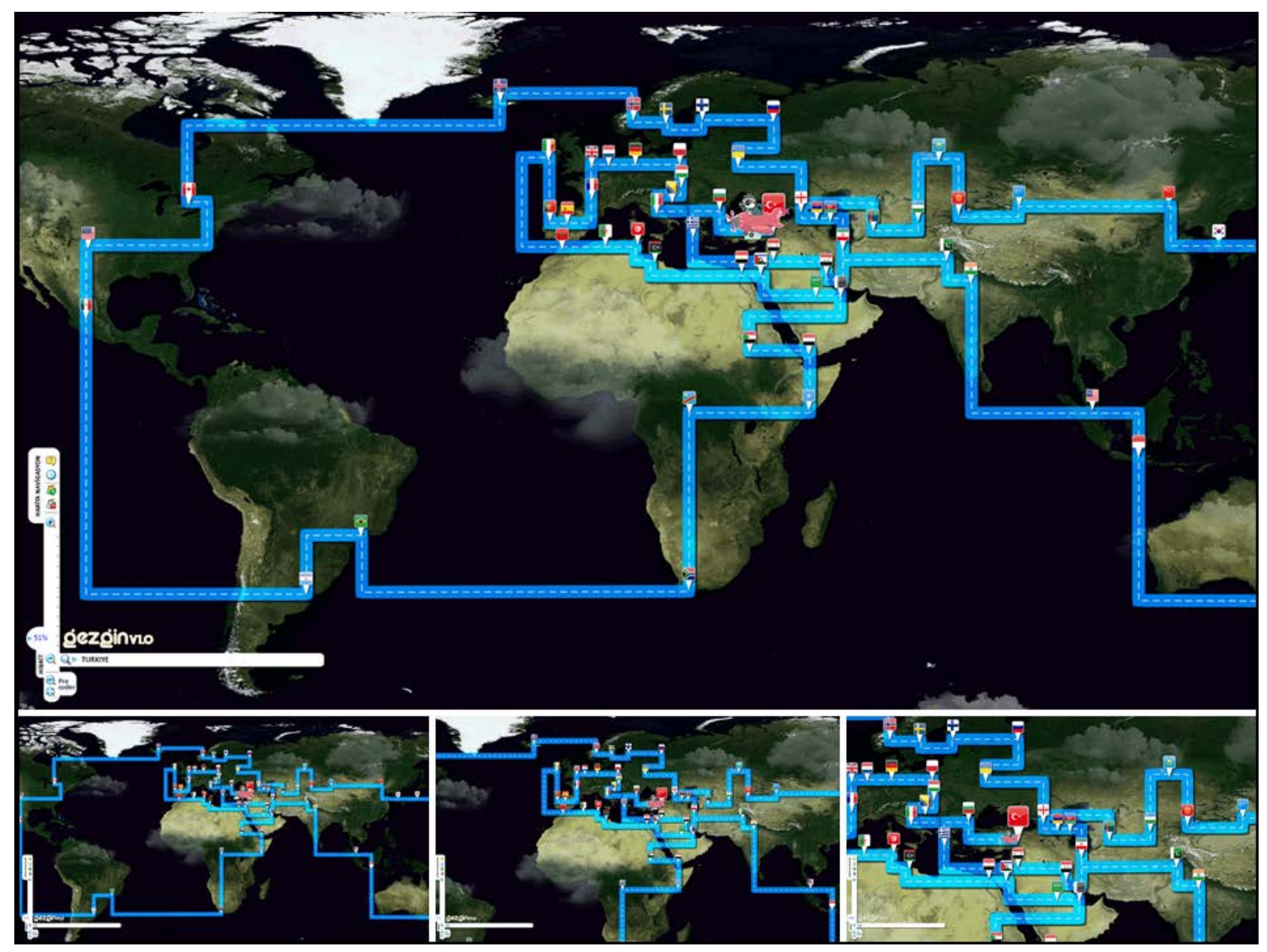

Fig. 1. The interface of Gezgin with completed learning tasks

\section{Supportive information}

Various information resources should be created for students to fulfil the learning tasks created in the first stage of the 4C/ID instructional design model. These sources students refer to while using their skills were defined as cognitive strategies. Information sources that provided a bridge between 


\section{ZEKERİYA FATİH İNEÇ}

prior knowledge and the knowledge reached in solving problems also helped to compare peers' ideas critically (van Merriënboer, 2019, pp. 5-6).

The supportive information structure of Gezgin was created with dynamic information windows reflecting the skills of the social studies course, such as using evidence and research, environmental literacy, empathy, financial literacy, noticing prejudices with stereotypes, decisionmaking, location analysis, perception of location, political literacy, and understanding of time and chronology. Designed as in-game popup windows, they can also reflect multimedia elements. Application programming interface from companies such as YouTube might be easily integrated into the Gezgin's supporting information windows, allowing customized multimedia elements to be available to users (İneç, 2020, pp. 264-266).

\section{Procedural information}

At this stage, the methods and procedures to be employed for learning tasks were evaluated. In a broader sense, the systematic procedure to be followed in reflecting the supportive information to the learning tasks was determined (van Merriënboer, 2019, pp. 6-7). The procedural information structure of Gezgin was reflected depending on learning methods and techniques. Within this framework, Gezgin was designed as a game that runs according to the principles of evidence and game-based learning, from close to far, from simple to complex learning principles. The procedural base of Gezgin was created in line with the following acquisitions (i.e. outcome) anticipated by the Ministry of National Education of Turkey regarding the Global Connections learning area (MoNE, 2018):

- Outcome.4.7.1. It introduces various countries around the world.

- Outcome.4.7.2. It understands the relations with Turkey's neighbours and other Turkish Republics.

- Outcome.4.7.3. It compares the cultural elements of various countries with the cultural elements of our country (i.e. Turkey).

- Outcome.4.7.4. It shows respect to different cultures.

- Outcome.5.7.1. It explores the role of the residential area and its environment in economic relations between our country and other countries.

- Outcome.5.7.2. It discusses the effect of communication and transportation technology on economic relations among countries. relations.

- Outcome.5.7.3. It explains the importance of tourism in international

- Outcome.5.7.4. It gives examples of common heritage items found in various countries. 
DEVELOPING A GEO-GAME APPLICATION FOR GLOBAL CONNECTIONS ...

- Outcome.6.7.1. It analyses the cultural, social, political, and economic relations of our country with Turkish Republics and neigh bouring states.

- Outcome.6.7.2. It analyses the economic relations of our country with other countries.

- Outcome.6.7.3. It analyses the roles our country takes in the international arena depending on the political, military, economic, and cultural characteristics it has.

- Outcome.6.7.4. It examines the effects of popular culture on our culture.

- Outcome.7.7.1. It gives examples of organizations Turkey is a member of.

- Outcome.7.7.2. It recognizes economic zones and organizations Turkey has a relationship with.

- Outcome.7.7.3. It questions the stereotyped judgments of various cultures.

- Outcome.7.7.4. It develops suggestions for solving global problems with classmates.

\section{Part-task procedures}

Part-task practices were designed to support learning tasks and to embody learning. In one aspect, these practices enabled the theory to find a response in practice. Accordingly, it was understood that part-task practices had an aspect of reflection (van Merriënboer, 2019, pp. 7-8). The semi-task applications of Gezgin are created by determining the skills in the supportive information stage and the user notes which are suitable for the teaching methods, techniques, and gains envisaged in the operational knowledge stage, adding them to the Gezgin database and displaying them in the supporting information windows. In part-task practices, the values such as sensitivity to cultural heritage, respect, and peace predicted in Global Connections learning area were also included. When Gezgin was regarded from this perspective, it was understood to have an ethnopedagogical point of view (Sándor, 2019) (Figure 2). 


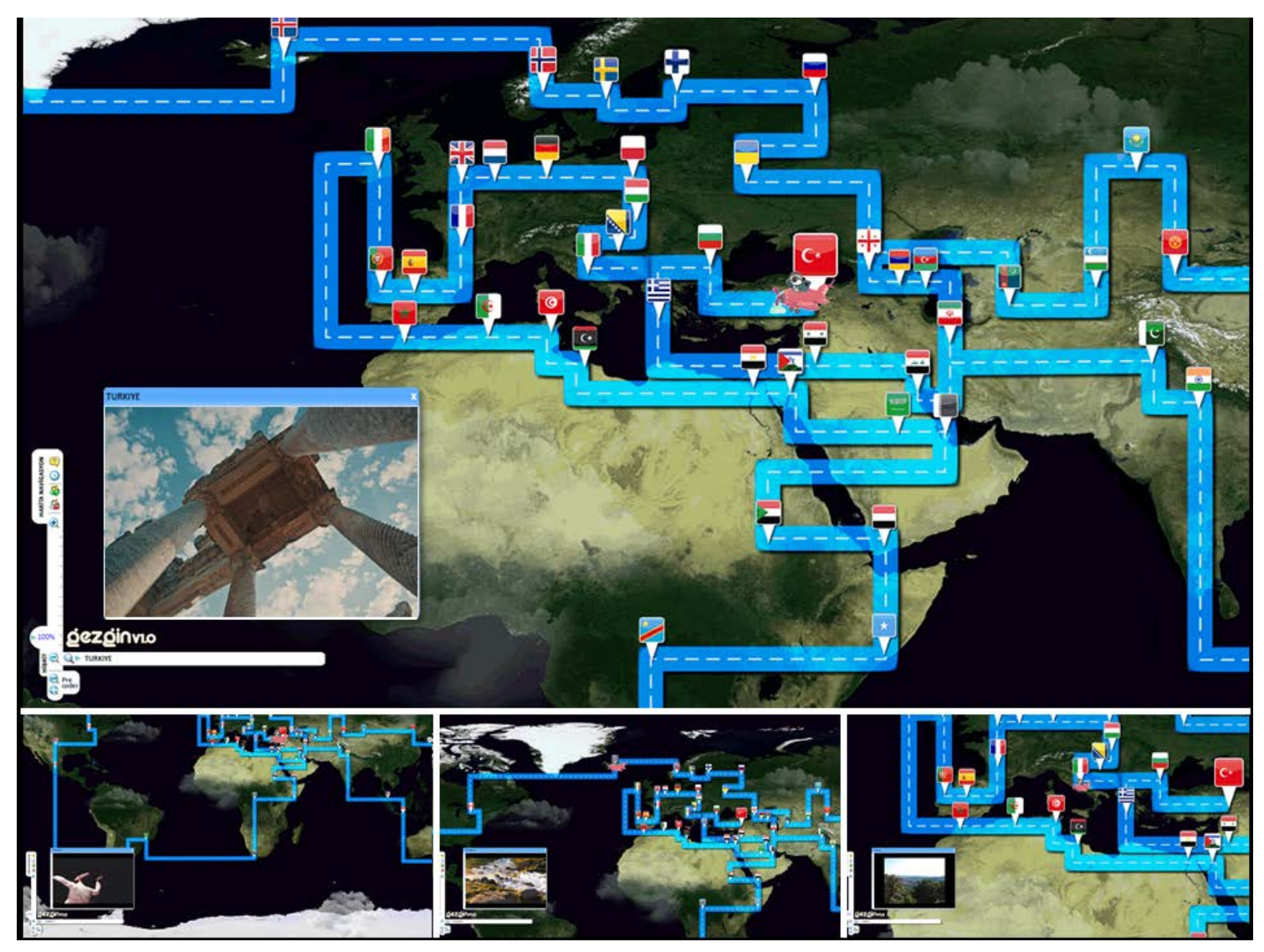

Fig. 2. Gezgin

\section{RESULTS}

The findings related to determining the reflection of acquisitions, values, and skills in the Global Connections learning area on Gezgin were presented in Table 2, Table 3 and Table 4.

Table 2. Reflection of acquisitions in Gezgin

\begin{tabular}{|c|c|c|c|}
\hline & \multirow{2}{*}{ Acquisitions } & \multicolumn{2}{|c|}{ Views } \\
\hline \multirow{6}{*}{$\begin{array}{l}\frac{0}{0} \\
\mathbb{0} \\
0 \\
5 \\
+ \\
+\end{array}$} & & Negative & Positive \\
\hline & $\begin{array}{l}\text { Outcome.4.7.1. It introduces various countries around the } \\
\text { world. }\end{array}$ & - & $\begin{array}{l}\mathrm{E} 1, \mathrm{E} 2, \mathrm{E} 3 \\
\mathrm{E} 4, \mathrm{E} 5\end{array}$ \\
\hline & $\begin{array}{l}\text { Outcome.4.7.2. It understands the relations with Turkey's } \\
\text { neighbours and other Turkish Republics. }\end{array}$ & E2 & $\begin{array}{l}\mathrm{E} 1, \mathrm{E} 3, \mathrm{E} 4, \\
\mathrm{E} 5\end{array}$ \\
\hline & $\begin{array}{l}\text { Outcome.4.7.3. It compares the cultural elements of } \\
\text { various countries with the cultural elements of our country. }\end{array}$ & - & $\begin{array}{l}\mathrm{E} 1, \mathrm{E} 2, \mathrm{E} 3 \\
\mathrm{E} 4, \mathrm{E} 5\end{array}$ \\
\hline & Outcome.4.7.4. It shows respect to different cultures. & $\mathrm{E2}, \mathrm{E} 4$ & $E 1, E 3, E 5$ \\
\hline & Percentage \% & $\% 15$ & $\% 85$ \\
\hline
\end{tabular}


DEVELOPING A GEO-GAME APPLICATION FOR GLOBAL CONNECTIONS ...

\begin{tabular}{|c|c|c|c|}
\hline \multirow{5}{*}{$\begin{array}{l}\frac{0}{0} \\
\mathbb{0} \\
5 \\
5 \\
\text { in }\end{array}$} & $\begin{array}{l}\text { Outcome.5.7.1. It explores the role of the residential area } \\
\text { and its environment in economic relations between our } \\
\text { country and other countries. }\end{array}$ & $E 2, E 3, E 4$ & $\mathrm{E} 1, \mathrm{E} 5$ \\
\hline & $\begin{array}{l}\text { Outcome.5.7.2. It discusses the effect of communication } \\
\text { and transportation technology on economic relations } \\
\text { among countries. }\end{array}$ & $E 2, E 3, E 4$ & $\mathrm{E} 1, \mathrm{E} 5$ \\
\hline & $\begin{array}{l}\text { Outcome.5.7.3. It explains the importance of tourism in } \\
\text { international relations. }\end{array}$ & E4 & $\begin{array}{l}\mathrm{E} 1, \mathrm{E} 2, \mathrm{E3}, \\
\mathrm{E5}\end{array}$ \\
\hline & $\begin{array}{l}\text { Outcome.5.7.4. It gives examples of common heritage } \\
\text { items found in various countries. }\end{array}$ & - & $\begin{array}{l}\text { E1, E2, E3, } \\
\text { E4, E5 }\end{array}$ \\
\hline & Percentage \% & $\% 35$ & $\% 65$ \\
\hline \multirow{5}{*}{$\begin{array}{l}0 \\
0 \\
0 \\
0 \\
0 \\
5 \\
0\end{array}$} & $\begin{array}{l}\text { Outcome.6.7.1. It analyses the cultural, social, political, } \\
\text { and economic relations of our country with Turkish } \\
\text { Republics and neighbouring states. }\end{array}$ & $\overline{E 2}$ & $\begin{array}{l}\mathrm{E} 1, \mathrm{E3}, \mathrm{E4}, \\
\mathrm{E5}\end{array}$ \\
\hline & $\begin{array}{l}\text { Outcome.6.7.2. It analyses the economic relations of our } \\
\text { country with other countries. }\end{array}$ & $E 2, E 3, E 4$ & $\mathrm{E} 1, \mathrm{E} 5$ \\
\hline & $\begin{array}{l}\text { Outcome.6.7.3. It analyses the roles our country takes in } \\
\text { the international arena, depending on the political, } \\
\text { military, economic and cultural characteristics it has. }\end{array}$ & E4 & $\begin{array}{l}\mathrm{E} 1, \mathrm{E2}, \mathrm{E3}, \\
\mathrm{E5}\end{array}$ \\
\hline & $\begin{array}{l}\text { Outcome.6.7.4. It exam ines the effects of popular culture } \\
\text { on our culture. }\end{array}$ & $E 2, E 4$ & $\mathrm{E} 1, \mathrm{E} 3, \mathrm{E} 5$ \\
\hline & Percentage \% & $\% 35$ & $\% 65$ \\
\hline \multirow{5}{*}{$\begin{array}{l}0 \\
\frac{0}{0} \\
\frac{0}{0} \\
\vdots \\
⿱ 亠 乂\end{array}$} & $\begin{array}{l}\text { Outcome.7.7.1. It gives exam ples of organizations Turkey } \\
\text { is a member of. }\end{array}$ & $E 2, E 3, E 4$ & $\mathrm{E} 1, \mathrm{E5}$ \\
\hline & $\begin{array}{l}\text { Outcome.7.7.2. It recognizes economic zones and } \\
\text { organizations Turkey has a relationship with. }\end{array}$ & $E 2, E 3, E 4$ & $\mathrm{E} 1, \mathrm{E} 5$ \\
\hline & $\begin{array}{l}\text { Outcome.7.7.3. It questions the stereotyped judgments of } \\
\text { various cultures. }\end{array}$ & $E 2, E 4$ & $\mathrm{E} 1, \mathrm{E} 3, \mathrm{E} 5$ \\
\hline & $\begin{array}{l}\text { Outcome.7.7.4. It develops suggestions for solving global } \\
\text { problems with classmates. }\end{array}$ & - & $\begin{array}{l}\mathrm{E} 1, \mathrm{E} 2, \mathrm{E} 3, \\
\text { E4, E5 }\end{array}$ \\
\hline & Percentage \% & $\% 40$ & $\% 60$ \\
\hline
\end{tabular}

When Table 2 was analysed, social studies education experts were noticed to state that the acquisitions in Global Connections learning area were mostly reflected. Fourth-grade acquisitions were reflected at the rate of $85 \%$, fifth and sixth-grade acquisitions were reflected at the rate of $65 \%$, and seventh-gradeacquisitions at the rate of $60 \%$.

Some of the expert opinions on reflecting the fourth-grade acquisitions were as follows:

Positive (Outcome.4.7.1.) - E3: “... it was very easy to travel countries and access all kinds of information."

Negative (Outcome.4.7.4.) - E2: "Students can see different cultures but even if they earn respect, how can they reflect this? After all, there is no one from that culture against them." 


\section{ZEKERİYA FATİH İNEÇ}

Some of the expert opinions on reflecting the fifth-grade acquisitions were as follows:

Positive (Outcome.5.7.4.) - E1: "There were common cultural heritage elements in all of the travels. It even made sense to choose travel images of travellers."

Negative (Outcome.5.7.2.) - E4: "It is an achievement that we are forced to give even in a normal lesson. However, I do not remember coming across it in the game. I do not think it can be reflected, either."

Some of the expert opinions on reflecting the sixth-grade acquisitions were as follows:

Positive (Outcome.6.7.1.) - E5: “In the contents, Turkey's ties with its neighbours and the Turkish Republics were sophisticatedly discussed. Even the content was quite much. If it is not interesting, anyone can get bored."

Negative (Outcome.6.7.2.) - E3: “Turkey's relations were discussed, but I do not remember that I encountered content on economic relations with other countries. I also felt that the relations differed from time to time."

Some of the expert opinions on reflecting the seventh-grade acquisitions were as follows:

Positive (Outcome.6.7.4.) - E2: "In fact, it is possible to explore the whole world while playing the game. Therefore, students also gain global awareness. On the other hand, an unexpected cultural partnership is created as we encounter our traditional games played in the Turkish Republics."

Negative (Outcome.7.7.1.) - E4: “I understand that the content can be updated as desired, but I do not think that Turkey's membership of international organizations was not listed enough in the notes provided in Gezgin."

Table 3. Reflection of values in Gezgin

\begin{tabular}{lcc}
\hline \multicolumn{1}{c}{ Values } & Vegative & Positive \\
Sensitivity to cultural heritage & - & E1, E2, E3, E4, E5 \\
Respect & E2, E4 & E1, E3, E5 \\
Peace & E2, E4 & E1, E3, E5 \\
\hline
\end{tabular}

When Table 3 was analysed, it is seen that social studies education experts underlined the positive reflection of values and they believed that the values in Global Connections learning area were mostly reflected in Gezgin. Sensitivity to cultural heritage was the value reflected at the rate of $100 \%$, 
respect was reflected at the rate of $60 \%$, and peace was reflected at the rate of $60 \%$.

Some of the expert opinions on reflecting the values were listed below.

Sensitivity to cultural heritage:

Positive-E1: “...While exploring the historical and cultural structures of the countries, I felt that they all belong to us, namely humanity. Of course, when I said so, I realized that I had gained an emotion through a game."

Respect:

Positive - E3: “As you discover countries on Gezgin, you also discover humanity. Colours, expressions, geographies probably differ, but the smiles and troubles caught on cameras tell us that we are not different. Perhaps we should understand this from globalization. Small and big human beings as big and small as the world."

Negative - E2: “Does the viewer see various people and cultures enough to respect? Or do the images reflect the whole reality? We can see the most natural state of people in travellers' notes because some of the people caught on camera do not know that they are being viewed. That's why I think that the moment should be experienced directly. Respect is earned with real life experience."

\section{Peace:}

Positive - E5: "It is a strange feeling to realize as we explore differences that we are not different or have something we cannot share. The bad thing is that you have this feeling, and you cannot do anything about it."

Negative - E4: “I don't know if I am biased, but I think that with the current use of technology, technology cannot go beyond feelings. On the other hand, which one of the games brings peace? You say peace as much as you want, say human, say the world is dying. People do not play peace games; they play all kinds of war games. I have a lot to say, but whatever."

Table 4. Reflection of skills in Gezgin

\begin{tabular}{lll}
\hline Skills & \multicolumn{2}{c}{ Views } \\
Research & - & E1, E2, E3, E4, E5 \\
Empathy & E2, E4 & E1, E3, E5 \\
Creativity & - & E1, E2, E3, E4, E5 \\
Critical thinking & E2, E4 & E1, E3, E5 \\
Cooperation & E1, E2, E4 & E3, E5 \\
Problem-solving & E4 & E1, E2, E3, E5 \\
Noticing stereotyped judgment and prejudice & E2, E4 & E1, E3, E5 \\
\hline
\end{tabular}


When Table 4 was analysed, social studies education experts were noticed to state that the skills in Global Connections learning area were mostly reflected. The research skill was reflected $100 \%$, creativity $100 \%$, problem-solving $80 \%$, empathy $60 \%$, critical thinking $60 \%$, noticing the stereotyped judgment and prejudice $60 \%$, and cooperation $40 \%$.

Some of the expert opinions on reflecting the skills were listed below.

Research:

Positive - E1: “Exploring countries is all about researching."

Empathy:

Positive - E3: "You don't just visit countries. You transfer there and replace people. You feel. At this point, according to me, supporting this study with the use of technologies such as virtual reality or augmented reality increases the positivity of the study."

Negative - E4: “I really don't think technology can arouse emotion. Moreover, if this emotion is a positive one. When you look at the most downloaded games from Google Play Store, you will realize that nobody empathizes and cares about peace."

Creativity:

Positive - E2: "Students reach to real-world information. This knowledge enables students to reveal their creativity and understand global connections through acquisitions. Especially, the acquisitions related to carrying on collaborative work will prioritize students' creativity."

\section{Critical thinking:}

Positive - E5: "For example, even the symbols of the flags on the routes will help children to think critically and to perceive the world. Because they know well that the flag topic draws students' attention in lessons and each one has a meaning."

Negative - E4: "Knowing it is not an easily acquired skill, it is difficult to imagine that we can fully provide it to be acquired. We like criticizing, but we misunderstood the true meaning of criticism."

\section{Cooperation:}

Positive - E3: "Students will act together in line with some acquisitions. Acquisitions require students to cooperate." 
Negative - E1: “Gezgin is a game played individually. I think there is no opportunity for cooperation. Maybe they can find solutions to problems when they play together in laboratories."

Problem-solving:

Positive - E2: "Students evaluate evidence to solve problems. The system is completely established on problem-solving. So, I guess it improves problem-solving skills."

Negative - E4: "Yes, there are problems, and solutions should be offered to problems. Where to assess them is a big problem. So, we must consider where to use these solutions."

Noticing stereotyped judgments and prejudice:

Positive - E5: “Our cultural characteristics are our differences. Realizing th is enables us to get rid of our stereotyped judgments and prejudices. This is frequently discussed in Gezgin notes. In fact, travelling around the world means introducing various cultures. As far as I can see, wherever you go in the world, everyone tries to help foreigners in their own way."

Negative - E2: "It does not make any sense to get rid of our judgments without mutual interaction and sharing. It is necessary to live and see. It is necessary to witness this. You must see the opposite of what is in your mind over and over again."

Table 5. General views

\begin{tabular}{llc}
\hline Themes & Views & Views \\
Positive & Possible to support the curriculum. & E2, E3 \\
& Possible to create different experiences. & E5 \\
& Possible to concretize theoretical information. & E1 \\
Indecisive & Possible to be tested on students. & E4 \\
\hline
\end{tabular}

When Table 5 was analysed, it was noticed that social sciences experts expressed their general views about Gezgin as possible to support curriculum $(f=2)$, possible to create different experiences $(f=1)$ and possible to concretize theoretical information $(f=1)$ under the theme of positivity and possible to be tested in students $(f=1)$ under the theme of indecisiveness.

Some of the general views of the social studies education experts were listed below. 
Positive:

Possible to support the curriculum. - E3: "Towards the end of the practice, I realized that we were playing games on the curriculum. It was possible to support the curriculum. Especially the skill dimension was much more significant."

Possible to create different experiences. - E5: “I used to think that our biggest limitation was learning from real-life while having fun. This will provide a very different experience for students. In fact, the children of today get bored of everything in ten minutes. I do not know if the constant updating of the content would be enough to overcome this, but it was quite different from what my own children played."

Possible to concretize theoretical information. - E1: "It is very difficult to concretize information on the internet during the pandemic process (COVID-19 pandemic). However, the situation seems different in such systems."

\section{Indecisive:}

Possible to be tested in students. - E4: "Learning with games is very nice. But we are speaking on behalf of children. I think their reaction is more important. So, I do not want to say anything definite."

\section{SCUSSI ON AND CONCLUSI ONS}

In this study, a dynamic geo-game called Gezgin was developed with the 4C/ID instructional design model to support the acquisitions and skills of the global connections learning area in social studies teaching applied in Turkey and to bring the predicted values to the fore. Furthermore, the reflections of the acquisitions, values, and skills in Gezgin and the opinions about the environment were determined with social studies education experts.

In accordance with the findings obtained from the first research question, it was determined that the acquisitions, values, and skills of the Global Connections learning area could mostly be reflected on Gezgin. However, because of the lack of research in literature, in which a learning area is fully addressed and the studies focusing on developing mapping such skills are limited (Dulamă, 2014; Dulamă \& Ilovan, 2016; Dulamă, Ilovan \& Nitoaia, 2016), a comprehensive comparison with the relevant literature could not be made.

However, findings obtained through the sub-questions show that Gezgin supports the values at the level of $73.3 \%$, skills at the level of $71.4 \%$, and acquisitions at the level of $68.7 \%$. This finding is in parallel to the literature proposing that the use of educational digital games is beneficial in teaching social studies (İşçi \& Yeşiltaş, 2020). It is also 
concluded from the study findings that a sense of empathy is needed in understanding respect and peace from the values that are tried to be reflected through the traveller. This issue is attributed to the use of technology as a tool in educational processes.

In addition, it is anticipated that technology and emotion interaction might be achieved with artificial intelligence studies. It is possible to make a similar interpretation for empathy and stereotyping-prejudice recognition skills. It is understood that the limitations in critical thinking and cooperation skills are related to instant communication tools in Gezgin. It is observed that the limitation of problem-solving skills is related to the interaction dimension on web platforms, unlike the others. It is thought that this situation can be overcome by integration to Web 3.0 technologies. When the acquisitions are examined individually, it is seen that the concepts such as institutions, organizations and relationships are not dealt with in detail in the traveller's notes. It is seen that the empathy skill is effective in comprehending the acquisitions.

However, the fact that the goals of the Global Connections learning area are gamified and presented to students at a rate of approximately $70 \%$ means that the study solves a problem in the literature to a great extent. These results are consistent with the literature indicating that acquisitions (Schaal et al., 2018), skills such as geographical investigation (Ahlqvist et al., 2014), relational thinking (Favier \& van der Schee, 2014), map reading, spatial thinking (Feulner \& Kremer, 2014; Tomaszewski et al., 2020), perception of space (Feulner, 2016), and values such as cultural heritage could be reflected (Kiefer, Matyas \& Schlieder, 2006).

The findings obtained from the second research question indicated that the preview related to Gezgin was positive, and thus it was possible to be used to support the curriculum, create diverse experiences in students and embody theoretical knowledge. However, it was also determined that the use of Gezgin in classrooms might create more meaningful results, as the students are a target group for such a practice. Then, it might be concluded that Gezgin can be used to support most of the topics in the social studies teaching curriculum in Turkey with Gezgin's dynamic and configurable architecture. With Gezgin, it is necessary to connect the provision of meaningful learning with different experiences and the meaning of knowledge through concrete lives to the unique Geo-Game experiences. As a further inquiry, much research conducted with students is needed to explain students' achievement levels of the objectives in the curriculum.

\section{RECOMMENDATIONS}

- Geo-games should be used to support other learning areas;

- Geo-games should be used to develop high-level skills;

- Geo-games applications should be used for creating spatial citizenship awareness. 


\section{ZEKERİYA FATİH İNEÇ}

\section{References}

Ahlqvist, O. \& Schlieder, C. (2018). Introducing Geogames and Geoplay: Characterizing an Emerging Research Field. In Ahlqvist, O. \& Schlieder, C. (eds.), Geogames and Geoplay. Game-based Approaches to the Analysis of Geo-Information (pp. 1-18). Switzerland: Springer.

Ahlqvist, O., Benkar, R., Mikula, B., Vatev, K., Ramnath, R., Heckler, A., Chen, Z. \& Jiang, P. (2014). Online Map Games-Playful Interaction with Complex RealWorld Issues. In AGILE Conference on Geographic Information Science, Castellon (Vol. 3). Retrieved 12 January 2021, from https://web.cse.ohiostate.edu/ ramnath.6/Education/F-

Ahlqvist_et_al_2014_Online_Map_Games.pdf

Creswell, J.W. (2015). Qualitative Research Approach. In Bütün, M. \& Demir, S.B. (Trans. ed.), Qualitative Inquiry and Research Design: Choosing Among Five Approaches (pp. 69-110). Ankara: Siyasal Publication.

Doğanay, A. (2016). Sosyal Bilgiler Eğitiminde Problem Çözme [Problem Solving in Social Studies Education]. In Dilek, D. (ed.), Sosyal Bilgiler Eğitimi [Social Studies Education] (pp. 403-414). Pegem Academy: Ankara.

Dulamă, M.E. \& Ilovan, O.-R. (2016). How Powerful is Feedforward in University Education? A Case Study in Romanian Geographical Education on Increasing Learning Efficiency. Educational Sciences: Theory \& Practice (ESTP), Kuram ve Uygulamada Eğitim Bilimleri (KUYEB), 16(3), 827-848. DOI: 10.12738/estp.2016.3.0392.

Dulamă, M.E. (2014). The Use of Geographic Thematic Maps in E-Learning. Exemplification: Bobota Village, Romania. In Vlada, M., Albeanu, G. \& Popovici, D.M. (eds.), Proceedings of the 9th International Conference on Virtual Learning (pp. 52-59). București: Editura Universității.

Dulamă, M.E., Ilovan, O.-R. \& Niţoaia, A. (2016). Forming and Assessing the Competence to Elaborate Proposals of Spatial Planning Measures for Hydrographical Basins. PedActa, 6(1), 16-27.

Favier, T.T. \& van der Schee, J.A. (2014). The Effects of Geography Lessons with Geospatial Technologies on the Development of High School Students' Relational Thinking. Computers \& Education, 76, 225-236.

Feulner, B. \& Kremer, D. (2014). Using Geogames to Foster Spatial Thinking. In Vogler, R., Car, A., Strobl, J. \& Griesebner, G. (eds.), GI_Forum 2014. Geovisualisation, Society and Learning (pp. 344-347). Wichmann, Berlin: Offenbach.

Feulner, B. (2016). Geogames In Geography Education. A Design-Based Research Study. In Proceedings of the Workshop on Geogames and Geoplay. In AGILE 2016, Helsinki, June 14-17, 2016. Retrieved 12 January 2021, from http://www.geogamesteam.org/agile2016/submissions/Feulner_Geography_Education.pdf

Ihamaki, P. (2015). Design 'the Pori Hidden Beauties Geocaching Series': Computersupported Collaborative Web-based Learning and Sharing Experiences. International J ournal of Web Based Communities, 11(2), 131-152.

İneç, Z.F. (2012). Web Based Geographical Information System Application in Social Studies Education. (Unpublished master thesis). Erzincan University, Institute of Social Sciences, Erzincan, Turkey. 
İneç, Z.F. (2020). Öğrenme Öğretme Süreçleri için API Örnekleri: Statik ve Dinamik Harita Oluşturma [API Examples for Learning and Teaching Processes: Creating Static and Dynamic Maps]. In Kozikoğlu, İ. (ed.), Eğitimde Güncel Yaklaşımlar [Current Approaches to Education] (pp. 247-288). Ankara: Pegem Academy Publishing.

İşçi, T.G. \& Yeşiltaş, E. (2020). The Use of Digital Game Development Software in the Social Studies Teaching and Related to This Views Social Studies Preservice. Turkish Scientific Researches J ournal, 5(2), 159-183.

Kiefer, P., Matyas, S. \& Schlieder, C. (2006) Learning about Cultural Heritage by Playing Geogames. In Harper, R., Rauterberg, M. \& Combetto, M. (eds.), Entertainment Computing - ICEC 2006. ICEC 2006. Lecture Notes in Computer Science, v.4161. Springer, Berlin, Heidelberg. https://doi.org/10.1007/11872320_26

Miles, M.B. \& Huberman, A.M. (1994). Qualitative Data Analysis: An Expanded Sourcebook (2 ${ }^{\text {nd }}$ ed.). California: SAGE Publications.

Ministry of National Education [MoNE] (2018). Social Studies Course Curriculum. Retrieved 21 November 2020, from http://mufredat.meb.gov.tr/Dosyalar/201812103847686SOSYAL\%20B\%C4\%BOLG\%C4\%BOLER\%20\%C3\%96\%C4\%9ERET\%C4\%B0 M\%20PROGRAMI\%20.pdf

Oturak Eyecisoy, H. (2014). The Opinions of Social Science Teachers about InService Training Programs: The Sample of Denizli. (Unpublished master thesis). Pamukkale University, Educational Sciences Institute, Denizli, Turkey.

Patton, M.Q. (2018). Diversity in Qualitative Research, Theoretical Orientations. In Bütün, M. \& Demir, S.B. (Trans. ed.), Qualitative Research \& Evaluation Methods (pp. 75-142). Ankara: Pegem Academy Publishing.

Paulus, G., Scheriau, H. \& Piechl, T. (2007). Geogames - A Fun-based Concept to Interest Grammar School Students in Spatial Sciences. In 10th AGILE International Conference on Geographic Information Science, Denmark, 2007. Retrieved 21 November 2020, from https://agileonline.org/conference_paper/cds/agile_2007/ proc/pdf/167_pdf.pdf

Safran, M. (2014). Sosyal Bilgiler Öğretimine Bakış [Overview of Social Studies Teaching]. In Tay, B. \& Öcal, A. (eds.), Özel Öğretim Yöntemleriyle Sosyal Bilgiler Ögretimi [Teaching Social Studies with Special Education Methods] (pp. 2-18). Ankara: Pegem Academy Publishing.

Sándor, I. (2019). Ethnopedagogy: The Term and Content. Acta Educationis Generalis, 9(3), 105-117. DOI: 10.2478/atd-2019-0016

Schaal, S., Otto, S., Schaal, S. \& Lude, A. (2018) Game-Related Enjoyment or Personal Pre-Requisites - Which Is the Crucial Factor When Using Geogames to Encourage Adolescents to Value Local Biodiversity. International Journal of Science Education, 8(3), 213-226.

DOI: $10.1080 / 21548455.2018 .1441571$

Schaal, S., Schaal, S. \& Lude, A. (2015). Digital Geogames to Foster Local Biodiversity. I nternational J ournal for Transformative Research, 2(2), 16-29.

Schlieder, C., Kiefer, P. \& Matyas, S. (2006). Geogames: Designing Location-Based Games from Classic Board Games. I EEE I ntelligent Systems, 21, 40-46. 
Stöckli, R. (2004). December, Blue Marble Next Generation. NASA Visible Earth: A Catalog of NASA I mages and Animations of Our Home Planet. Retrieved 21 November 2020, from https://visibleearth.nasa.gov/collection/1484/bluemarble

Tomaszewski, B. \& Schwartz, D.I. (2017). Critical Spatial Thinking and Serious Geogames: A Position. In AGILE Workshop on Geogames and Geoplay Wageningen, May 09, 2017. Retrieved 21 November 2020, from http://www.geogamesteam.org/agile2017/submissions/Critical_SpatialThinking_AGILE_2017.pdf

Tomaszewski, B., Walker, A., Gawlik, E., Lane, C., Williams, S., Orieta, D., McDaniel, C., Plummer, M., Nair, A., San Jose, N., Terrell, N., Pecsok, K., Thomley, E., Mahoney, E., Haberlack, E. \& Schwartz, D. (2020). Supporting Disaster Resilience Spatial Thinking with Serious Geogames: Project Lily Pad. ISPRS Int. J. Geo-Inf, 9(6), 1-22. DOI: https://doi.org/10.3390/ijgi9060405

Van Merriënboer, J.J.G. (2019). The Four-Component Instructional Design Model: An Overview of Its Main Design Principles. Maastricht, The Netherlands: Maastricht University.

Yıldırım, A. \& Şimşek, H. (2013). Sosyal Bilimlerde Nitel Araştırma Yöntemleri [Qualitative Research Methods in the Social Sciences]. Ankara: Seçkin Publishing. 